\title{
LIVRO DE IMAGEM: POSSIBILIDADES DE LEITURA
}

\author{
Flávia Brocchetto Ramos (UCS) \\ Quem conta um conto, aumenta um ponto. \\ (ditado popular) \\ "Para ouvir o sussurro do mar o homem de lata se inscreve \\ no mar" \\ (BARROS, 2010, p.25)
}

Resumo: Pesquisas acerca de produtos culturais destinados à infância na contemporaneidade incluem o livro literário - modalidade livro de imagem - como um objeto presente nesse universo. Tais obras tendem a ser entendidas como produtos mais fáceis para serem lidos do que títulos de natureza híbrida, estes formados pela articulação da palavra e da ilustração. No entanto, há elementos presentes na formação de livros de imagem que implicam operações mais complexas de leitura, haja vista a ausência de orientação verbal para o entendimento a ser dado às imagens que formam o livro. Assim, tomamos como foco para discussão a obra O tapete voador, de Caulos, selecionada pelo PNBE 2014, a fim de analisar o processo de construção do enredo, priorizando as relações intertextuais. Os sentidos, no título, emergem, prioritariamente, a partir da presença de dois personagens que permeiam as cenas e, ainda, de elementos visuais como cores e linhas que se mantêm. A leitura do título pressupõe a articulação de diversos elementos e conhecimentos prévios do leitor para que a concretização se efetive.

Palavras- chave: Livro de imagem, PNBE 2014, Mediação, Intertextualidade.

Abstract: Research carried out on cultural products aimed at contemporary childhood include literary books - in the category of wordless book- as an object that is present in this universe. They can be understood as products that are easier to be read than those of hybrid nature, which are formated by the articulation of words and illustrations. However, there are some elements present when formatting picture books and they imply more complex operations to 
read, once there is no verbal orietation for the understanding regarding the pictures that comprise the book. We focus our discussion on the book O tapete voador, by Caulos, which has been chosen by PNBE 2014, in order to analyze the construction of the plot, prioritizing intertextual relations. Meanings of the title emerge, especially, from the presence of two characters that permeate the scenes and also of visual elements such as colors and lines that remain. Reading the title presupposes the articulation of several elements and reader's previous knowledge so that concretization may take place.

Keywords: Wordless book, PNBE 2014, Mediation, Intertextuality.

\section{INTRODUÇÃO}

A literatura, commanifestação cultural, vai se transformando, juntamente com os seres humanos, de modo que o nosso entendimento do que seja literatura ultrapassa a fronteira do uso estético da palavra escrita ou, ainda, conceituação mais ampla que contempla manifestações orais como lendas, cantigas (CANDIDO, 1995). Ao elegermos a literatura infantil contemporânea como objeto de estudo, defendemos que a visualidade gera também universos literários, como é o caso, por exemplo, do livro de imagem, presente em acervos destinados a estudantes da escola básica brasileira. Esta modalidade discursiva que não se vale da palavra vem ganhando espaço dentro das produções de literatura infantil como produto cultural direcionado a estudantes não alfabetizados como se fosse um texto cuja exigência, no ato de leitura, por não ter a palavra, fosse menor. 
Nessa combinação, emergem temas e conflitos cujos enunciados seriam, por direito, ensinados e aprendidos na escola, para uma leitura mais completa, que vai além do enunciado verbal, considerando o livro de imagem como um todo de sentido. A partir da situação posta, propomo-nos a estudar: como o livro de imagem, presente em acervos do PNBE de anos iniciais do Ensino Fundamental, se constitui discursivamente, apelando ao seu destinatário? A opção por obras do Programa Nacional Biblioteca da Escola (PNBE) não é casual. Trabalhamos com obras literárias alocadas em bibliotecas escolares por meio do PNBE. Tal ação, a partir do Decreto $n^{\circ} 7559$, de 1 을 de setembro de 2011, que dispõe sobre o Plano Nacional do Livro e Leitura - PNLL -, é uma política pública de Estado que visa à promoção da leitura literária.

\section{A LINGUAGEM NA INFÂNCIA}

Somos seres de linguagem e, levando em conta o caráter dialógico, social e interativo da mesma, o leitor é também um ser social, efetivamente discursivo e que reconhece o outro e compartilha conhecimento, experiências e opiniões por ela independente do modo pelo qual se manifeste - verbal, gestual, visual. Defendemos ainda que o desenvolvimento cognitivo do ser humano ocorre pelas interações com o mundo social, mediadas pela linguagem, que também 
viabiliza o pensar humano sobre si mesmo e seu entorno. Ou seja, a linguagem é fundamental para a pessoa se constituir, se conhecer e se dizer. O sujeito, conforme Bakhtin (1981), é essencialmente dialógico, seu conhecimento é pautado nos discursos que elabora. Se o indivíduo se constitui pelas interações com os demais sujeitos, inferimos que estas interações têm essência verbal ou não verbal e que, quanto maior for o grau de interação, maior será sua capacidade de diálogo e de compreensão dos humanos. Encontramos exemplo de crianças interagindo com impressos e lendo muito antes de serem alfabetizadas, embora socialmente sejam tidas como não alfabetizadas e, consequentemente, não leitoras (Fig. 1).

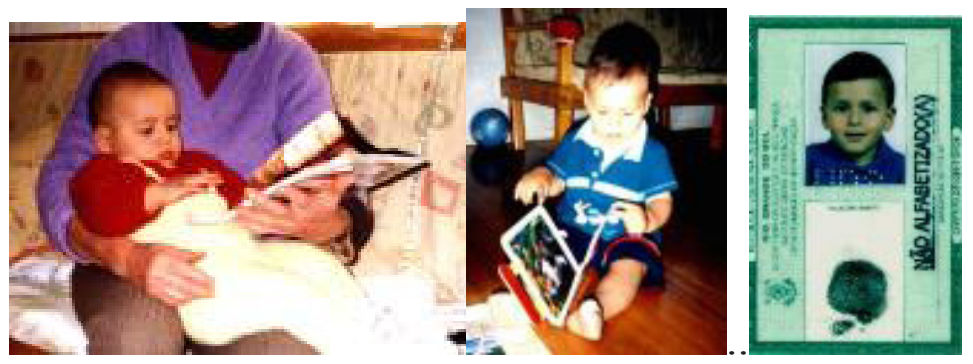

Fig. 1: Imagens de criança não alfabetizada

Fonte: acervo da autora.

Os exemplos de crianças manuseando impressos e interagindo com textos verbo-visuais se repetem na 
sociedade contemporânea. A infância aparece como leitora também em ilustrações de livros literários destinados a esse público. No título Se a lua pudesse falar, de Kate Banks (2000), a própria criança aparece como personagem e leitora e esses papéis se misturam na composição do enredo. A ilustração da obra mostra a criança lendo a visualidade do livro infantil e apropriando-se dessa linguagem (Fig. 2). Pela ilustração, vemos a criança juntamente com o adulto, interagindo com um livro ilustrado. Nas páginas seguintes, a ilustração do título lido sai das páginas do exemplar e entra na vida da criança leitora, posto que os personagens ilustrados no livro lido mesclam-se aos animais que adornam o quarto da leitora. A última figura mostra essa fusão materializada no sonho da menina. O sonho, na obra, aproxima elementos concretos do quarto onde a personagem dorme e aqueles oriundos da fiç̧ão, seja do âmbito verbal, seja do visual. A obra mostra, pois, que a criança, ao significar a visualidade do livro, apropria-se dos elementos ficcionais e os ressignifica no seu cotidiano. 


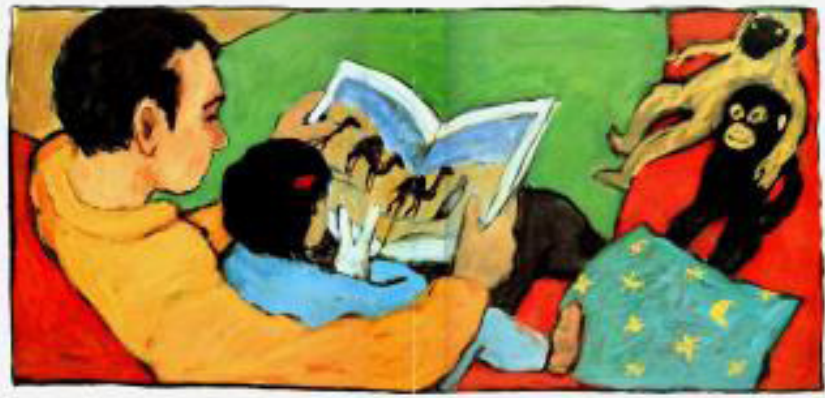

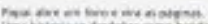

sentonesen 6

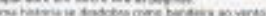
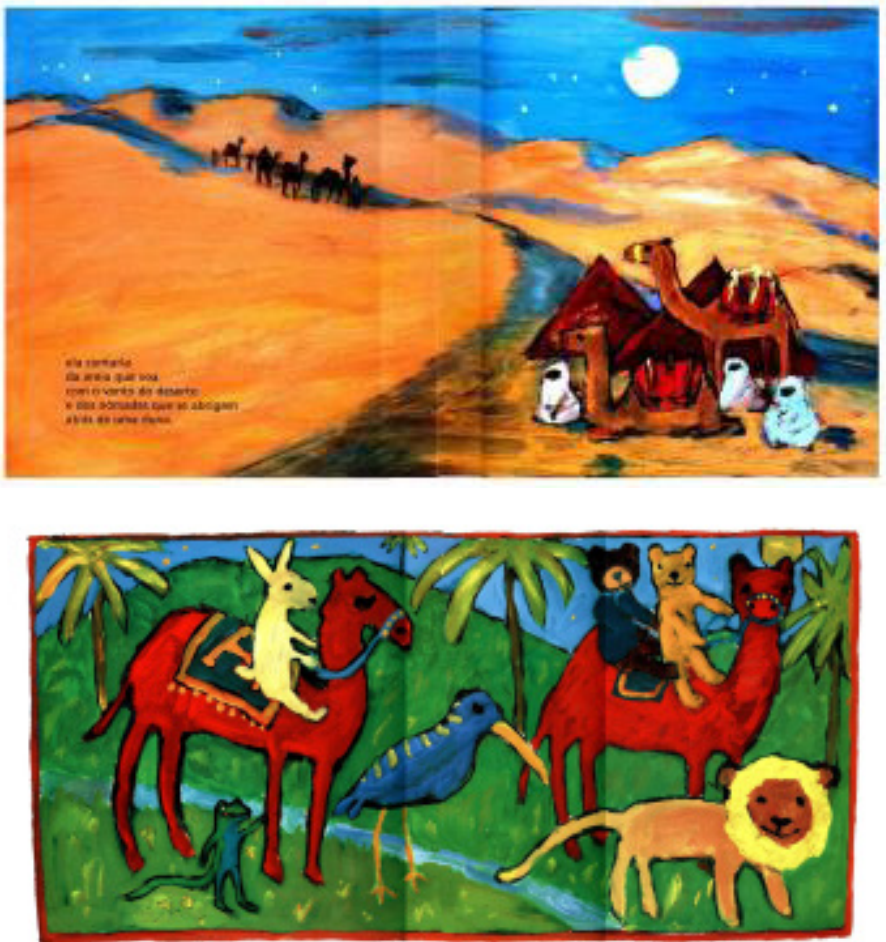

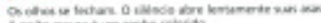

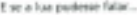

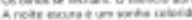

Fig. 2 - Imagens de criança leitora na ficção. Fonte: Banks (2000) 
A ilustração não tem papel meramente decorativo, mas constitutivo do leitor. As ilustrações dos livros infantis ou mesmo os livros só de imagem reúnem uma série de signos ideológicos capazes de engendrar um processo dialógico, que se reflete sobre a consciência de seu leitor/observador. As discussões bakhtinianas sobre as interações dialógicas e ideológicas na estruturação da consciência são possíveis de serem aplicadas aos estudos da imagem, que, como uma linguagem valorizada culturalmente, tem sido vinculada à produção literária para crianças, manifestando-se nos discursos escolhidos como adequados a tais leitores.

\section{LIVRO DE IMAGEM}

Frente ao exposto, elegemos como foco de estudo uma modalidade de livro produzida para criança que se forma apenas pelo domínio visual. Trata-se do livro de imagem, neste caso, aquele que produz uma narrativa visual. Conforme Ramos e Paiva (2014), a apresentação dos livros infantis tem se alterado e segue as tendências do mercado editorial. Alertam que:

Alguns livros infantis contemporâneos definem-se pelo mix: livro + objeto + ação, ou seja, por propiciar à criança um tempo convidativo de exploração tátil, apreciação, leitura e interação direta. São livros com montagens espetaculares, em 3D, 
dobraduras pop up, submetidos à arte dos engenheiros do papel, os quais assumem formatos tradicionais ou até então atípicos, como o de casas, castelos, sítios arqueológicos, teatros, palcos, tabuleiro de jogos, travesseiros, maletas etc. Alguns destes livros de nova geração assumem estratégias informativas e outros, literárias. (RAMOS; PAIVA, 2014, p.429)

Ao pensarmos acerca do livro e da leitura, lembramonos de uma das cinco máximas de Ranghanatan - cada leitor tem o seu livro. Apoiadas nessa premissa, parece-nos que o mercado editorial tem se debatido, a fim de encontrar o livro para o leitor não alfabetizado. Nesse contexto, entre as obras literárias publicadas para a infância, estão os livros de imagem. Cabe a este artigo discutir a composição de um exemplar selecionado pelo PNBE - acervo dos anos iniciais do Ensino Fundamental. A necessidade de selecionar um título implica a eliminação de outros que poderiam ser objeto de estudo do artigo. Definimos como critério que a obra escolhida além de ser de natureza visual, também fosse construída a partir da intertextualidade.

O livro de imagem, no âmbito desta exposição, pertence ao gênero narrativo, pois, pela visualidade, é possível observar a passagem do tempo, assim como aspectos ligados à espacialidade e ainda à configuração dos personagens, 
responsáveis pelo fio narrativo. No que tange à composição da obra literária, Kristeva argumenta que:

[...] todo texto se constrói como mosaico de citações, todo texto é absorção e transformação de um outro texto. Em lugar da noção de intersubjetividade instala-se a de intertextualidade, e a linguagem poética lê-se pelo menos como dupla. (KRISTEVA, 1974, p.68)

Elegemos assim, para discussão, a obra $O$ tapete voador, de Caulos (2013). O título reapresenta o tema da viagem. A capa do exemplar (Fig. 3) pouco revela porque, além do título com letras, formatos e cores variados; há uma imagem de fundo que lembra o céu com nuvens e, nas letras do título, animais mostram suas caras; não havendo indicativos acerca de enredo.

O conflito começa a ser posto de modo mais explícito na página 7, quando parte de um menino e de um cachorro se mostram, mas o rosto do menino é cortado intencionalmente pela borda da página. Virando a folha, no verso da página, o cachorro reaparece na mesma posição e vê-se o corpo do menino na totalidade. Se antes tínhamos uma estrela no cenário, agora várias aparecem e também a lua, sinalizando a noite. Há aspectos que tendem a orientar o leitor - sempre há molduras nas cenas, o fundo das páginas é branco, o 
menino e o cão são os personagens que aparecem durante toda a história. Trata-se de uma história de viagem - viagem pelo mundo, pela leitura? Seria uma metáfora da leitura?

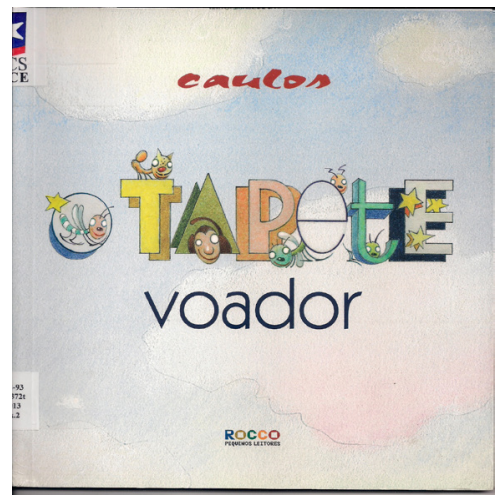

Fig. 3: Capa de O tapete voador Fonte: Caulos (2013)

O menino e o cachorro entram no exemplar que o leitor manuseia e, após o menino pegar um livro, ambos circulam por vários cenários, visualizam pirâmides egípcias, Big Ben, Torre Eiffel, Torre de Pisa, Cristo Redentor. Além de observarem cenários reais, os protagonistas atêm-se ao clímax de algumas histórias: Peter Pan agarrado por Capitão Gancho; bruxa entregando uma maçã vermelha à Banca de Neve, ou seja, os lugares visitados são aqueles que encontramos em mapas, mas também aqueles construídos pela imaginação após a leitura de livros escritos em diferentes tempos e lugares. Os protagonistas chegam até o espaço sideral onde se juntam à 
lua, Saturno e um foguete. Por fim, o tapete pousa na terra, e o menino, segurando o livro, juntamente com seu cachorro, rega uma pequena plantinha que tem só duas folhas. Os detalhes do cenário são omitidos, exigindo que o leitor atue sobre o branco da página e configure detalhes, por exemplo, do espaço onde Capitão Gancho agarra Peter Pan ou onde Alice corre atrás do coelho.

Essa história de viagem acontece no espaço e também no tempo, duas categorias fundamentais da narrativa. Os personagens percorrem momentos históricos diversos: após pegar o livro, vão ao período jurássico e conhecem dinossauros, acompanham as caravelas (que chegam e/ou partem) e índios, passam por ampulheta, que serve como porta para se deslocarem, saindo da ficção e chegando a um passado mais remoto. Enfim, o jogo temporal é um dos aspectos que desafia e mobiliza o leitor, de modo que a presença da figura do mediador torna-se fundamental, caso a criança ainda não tenha referências visuais para elementos como caravelas e até mesmo símbolos de outros países como Torre Eiffel, Torre de Pisa, gondolas de Veneza, entre outros (Fig. 4).

Não há conflito posto, a sucessão de cenas gera fio narrativo tênue. Durante $\mathrm{o}$ enredo, são apresentados 
personagens infantis criados por Monteiro Lobato; Pinóquio, noutra cena, muitos animais, lembrando aqueles da arca de Noé. Os animais que têm asa acompanham os protagonistas na sequência do enredo.

- Quanto ao modo de enunciar, ou seja, aos aspectos ligados à formação das imagens, destacamos:

- O título se organiza por figuras que se deslocam espacial e temporalmente, desafiando o leitor infantil. Um menino e seu cão estabelecem o fio narrativo, atuando como elementos que orientam a significação do título. A aparência do protagonista tende a se repetir em todo o enredo. O traço simples e a ausência de detalhes na composição das figuras e dos cenários aproximam o exemplar do universo do leitor mirim, como pode ser percebido nas figuras inseridas neste artigo.

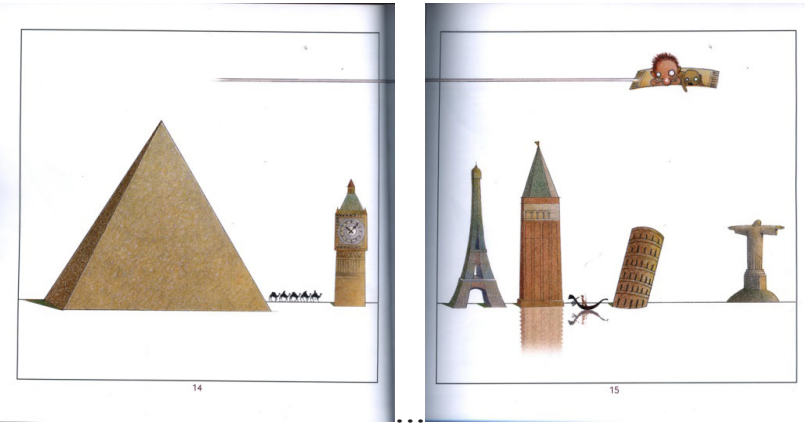

Fig. 4 - Passeio espacial dos protagonistas.

Fonte: Caulos (2013, p.14-15) 
- A presença do vermelho (e suas nuances) e os sentidos que podem ser construídos a partir dele. A cor marca o nome do autor na capa e na folha de rosto; na p. 3, aparece no bico do animal (que bicho é), a boca do menino e de seu cachorro, assim como os botões da porta da árvore onde está guardado o livro, cuja lombada e proteção de orelhas são da mesma cor. O vermelho, tradicionalmente, simboliza o princípio da vida, mas também o seu mistério (CHEVALIER; GHEERBRANT, 1993, p. 944-946); é uma cor que mobiliza o olhar do observador e também expressa a tensão da ação posta numa cena, como nas páginas 16 e 17. O Capitão Gancho (com chapéu e blusa listrada com vermelho) agarra Peter Pan e a maçã da mesma cor na mão da bruxa está alinhada ao laço, também vermelho, sobre a cabeça da Branca de Neve. O vermelho, aqui, poderia simbolizar a tensão do viver.

- Todas as cenas do miolo do livro estão emolduradas por uma linha preta. Essa moldura é rompida pelos protagonistas que se deslocam entre as várias imagens. O "rastro" do tapete voador corta a linha preta da moldura, alertando o leitor acerca da ação dos protagonistas.

- O corpo dos personagens está sempre posicionado dirigindo-se à direita do livro, reiterando o movimento de seguir em frente - o mesmo feito pelo leitor. Nesse sentido, 
cabe uma pergunta: o livro representa o que a leitura poderia provocar no leitor?

- O cenário de abertura e desfecho da história são similares, mas durante o enredo o protagonista sofre modificações, mesmo que não sejam aparentes (Fig. 5).
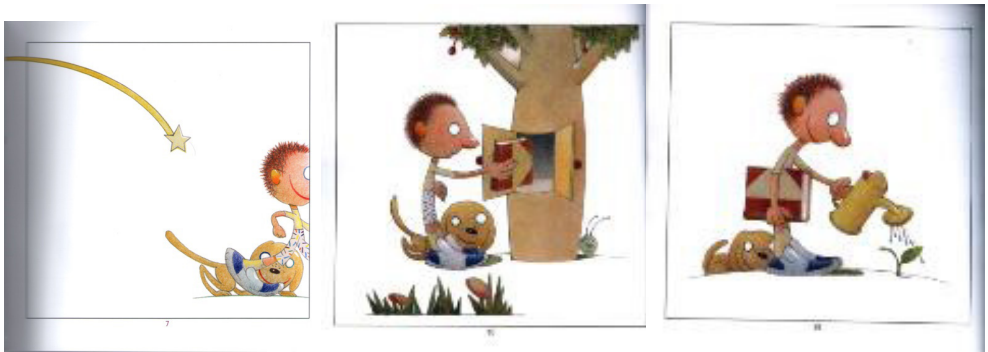

Fig. 5: Abertura e desfecho do enredo: protagonista seguindo em frente. Fonte: Caulos (2013, p.7, 10 e 38)

A ausência de palavra na construção do título desafia o leitor a criar a história, a enunciá-la mesmo que seja para si mesmo. Se o texto verbal anunciasse: "Era uma vez um menino que estava entediado em casa. Certo dia resolveu dar uma volta com seu cachorro e, no passeio, encontrou uma árvore. A árvore tinha duas portinhas no tronco...". A ausência da palavra, entretanto, pressupõe que a enunciação verbal do livro de imagens gere histórias diferentes ao interagir com diferentes leitores. Nem o cão nem o menino são nomeados, convidando o leitor a identificá-los.

Retomando as duas epígrafes deste artigo, passamos a discutir a composição da obra. A sabedoria popular alerta que, 
ao contar algo, inventamos um pouco. Nesse caso, muitos personagens e cenários conhecidos são reapresentados, mas para que o leitor consiga produzir sentido ao enredo veiculado no título, há que conhecer o universo representado, ou seja, algumas figuras que compõem o exemplar estão presentes em outras narrativas e o leitor deve identificá-las para tecer o novo enredo. O titulo reúne, por exemplo, Capitão Gancho, a bruxa e Branca de Neve, Alice, de modo que o sentido, nesse título, pressupõe do leitor o reconhecimento das figuras oriundas de outras narrativas, ou seja, pressupõe o conhecimento de outras histórias (Fig. 6).
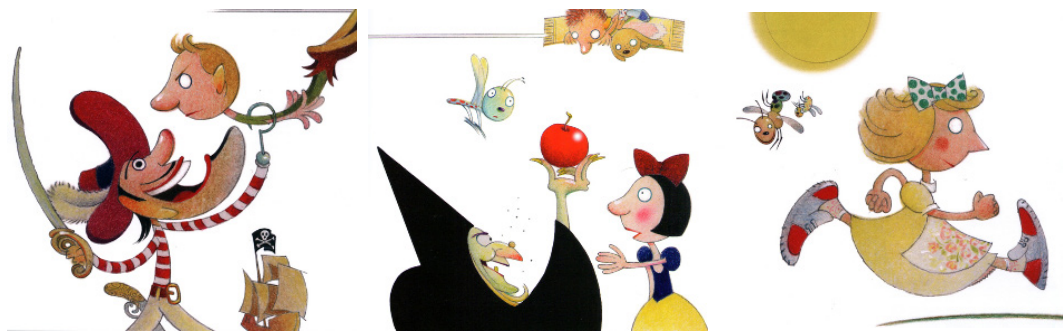

Fig. 6: Presença de personagens da literatura infantil universal. Fonte: Caulos (2013, p.16, 17 e 18)

Por tratar-se de texto literário, a obra contempla dados que favorecem a aproximação com o leitor visado e outros que a desafiam. A figura do menino e seu cão asseguram o viés narrativo, o traço simplificado favorece a identificação dos seres, assim como a moldura nas páginas e ainda o emprego de apenas um plano na apresentação das cenas são aspectos 
que tornam os quadros mais acessíveis ao leitor iniciante.

O titulo da obra remete a um elemento fantasioso presente em conto popular - o tapete voador - que leva o protagonista a espaços inacessíveis. Essa proposta é implementada na obra e, com esse passaporte, o leitor pode aproximar o que é distante. O grande desafio posto na obra, após a identificação de imagens provindas de outros cenários reais ou ficcionais, é articular sentidos para as figuras. A natureza intertextual se impõe na composição de $O$ tapete voador e o leitor é convocado a agir sobre as imagens.

Se o conceito de infância passa por mudanças, a proposta do livro de literatura para esse destinatário também sofre alterações. A tradição de a literatura ser um texto impresso divide espaço com títulos formados pela visualidade. Evidencia-se ainda o fato de o livro deixar de lado um enredo tradicional com exposição, complicação, transformação, resolução e situação final (esquema quinário) e surge a obra feita por recortes de outras histórias, mas tais recortes são materializados por imagens.

Pela natureza intertextual, a proposta do título pode parecer muito densa para a criança. No entanto, se ela é capaz, como demostra a figura 1 , de interagir com revista e ainda com narrativas verbo-visuais, o título pensado e 
apresentado apenas pela linguagem visual - tendo como protagonista um menino e animal de estimação - parece ser apropriado e legível à infância contemporânea.

Citações, referências, alusões, epígrafes, paráfrases, paródias são algumas das formas de intertextualidade empregadas pelos escritores ao marcar o diálogo com a tradição. Esses recursos têm ingressado no âmbito da literatura infantil e não há como negar a intertextualidade na composição do texto literário para criança. No entanto, a obra eleita inova por ser de natureza visual e por congregar dados da realidade e da ficção. O título sintetiza, pois, que fazer literatura infantil, hoje, implica conversar com a tradição e mobilizar o leitor para agir sobre o universo construído ficcionalmente. O leitor criança é tido como sujeito e, portanto, ativo na construção do enredo.

\section{REFERÊNCIAS:}

Candido, A. (1995). Vários escritos (3a ed.). São Paulo: Duas cidades. BAKTHIN, Mikhail M. (1981) Marxismo e filosofia da linguagem. Problemas fundamentais do método sociológico na ciência da linguagem (2a ed.). São Paulo: Hucitec.

Banks, Kate (2000). Se a lua pudesse falar. São Paulo: Cosac \&Naify. Caulos (2013). O tapete voador. Rio de Janeiro: Rocco.

Chevalier, Jean \& Gheerbrant, Alain (1993). Dicionário de símbolos (7a ed.). Rio de Janeiro: José Olympio.

Kristeva, Julia (1974). Introdução à semanálise. São Paulo: Perspectiva. 
Ramos, Flávia Brocchetto (2014). A literatura me alcança pelas imagens que a constituem: reflexões epistolares. In PAIVA, A. \& SOARES, M. (Orgs.). PNBE na escola: literatura fora da caixa - Guia 2: Anos iniciais do Ensino Fundamental / Ministério da Educação ; elaborada pelo Centro de Alfabetização, Leitura e Escrita da Universidade Federal de Minas Gerais. Brasília: Ministério da Educação, Secretaria de Educação Básica.

. \& Paiva, Ana Paula (2014). A dimensão não verbal do livro literário para criança. Revista Contrapontos - Eletrônica (Vol. 14, n. 3, set-dez). In http://www6.univali.br/seer/index.php/rc/article/view/5919/ pdf 45 Acesso em Janeiro/ 2015.

Flávia Brocchetto Ramos: Bolsista Produtividade CNPq. Doutora em Letras pela PUCRS. Realizou estágio de pós-doutorado na FaE/UFMG. Líder do grupo de pesquisa Educação e linguagem, UCS/CNPq. Professora e pesquisadora na Universidade de Caxias do Sul. Autora de artigos, capítulos de livros e livros que discutem, em especial, a leitura literária na infância. Destaca-se a autoria do Livro Literatura infantil: de ponto a ponto e a coautoria do livro Interação e mediação de leitura literária para a infância, publicado pela Global. Email: ramos.fb@gmail.com. 